\title{
FAKTOR-FAKTOR PENENTU YANG MEMPENGARUHI PETANI MENANAM TANAMAN SELA DI ANTARA KARET DI SUMATERA SELATAN
}

\author{
Determinant Factors Influencing Farmers to Plant Rubber Intercrop \\ in South Sumatera \\ Iman Satra NUGRAHA ${ }^{*}$, Aprizal ALAMSYAH, \\ Dwi Shinta AGUSTINA, dan Lina Fatayati SYARIFA \\ Balai Penelitian Sembawa, Pusat Penelitian Karet \\ J1. Raya Palembang - P.Balai KM 29 Palembang 30001 Sumatera Selatan \\ *Email : iman_satra@yahoo.com
}

Diterima : 4 Agustus 2015 / Direvisi : 4 Februari 2016 / Disetujui : 16 Maret 2016

\begin{abstract}
The behavior of intercrops planting is practice by farmers for a quite long time. Moreover when the farmers income increased due to the higt rubber price, they still grow intercrop. The purpose of the research was to indentify and analyze dominant factors to practice intercropping. The study was conducted in Pangkul, Lubuk Bandung, and Marta Jaya Villages. Sampling was done purposively, while retrieval of data using a survey method through a structured interview. Analysis of the data were using stepwise anlysis with intercropping, rubber planting experience, education of farmers, the purpose of intercropping and main work wiht their coefficient value were 0.000001; $0.003 ; 0.16$; -0.07 , respectively. independet variables that had a positive effect on the behavior of intercropping were the revenue intercroppimg, rubber planting experiences and purpose in intercropping. While other independent varables had negative effect.
\end{abstract}

Keywords: Farmer behavior; stepwise regression; intercropping

\footnotetext{
Abstrak

Kebiasaan menanam tanaman sela telah lama dilakukan oleh petani. Namun, pada saat pendapatan petani meningkat karena harga karet tergolong tinggi petani karet masih membudayakan menanam tanaman sela. Oleh karena itu penelitian dilakukan untuk mengidentifikasi dan menganalisis faktor dominan yang mempengaruhi petani konsisten tanaman
}

sela. Penelitian dilakukan di Desa Pangkul (Kabupaten Muara Enim), Desa Lubuk Bandung (Kabupaten Ogan Ilir) dan Desa Marta Jaya (Kabupaten Ogan Komering Ulu). Pengambilan data dilakukan dengan menggunakan metode survei melalui wawancara secara terstruktur. Pengambilan sampel dilakukan secara purposive dengan jumlah sampel 43 responden. Pengolahan data menggunakan analisis regresi stepwise. Variabel yang berpengaruh kuat tersebut yaitu pendapatan tanaman sela, pengalaman berkebun, pendidikan petani, tujuan menanam tanaman sela dan pekerjaan pokok petani dengan masing-masing nilai koefesien adalah 0,$000001 ; 0,003 ;-0,03$; 0,$16 ;-0,07$. Variabel bebas yang berpengaruh positif terhadap perilaku menanam tanaman sela adalah pendapatan tanaman sela, pengalaman berkebun dan tujuan menanam tanaman sela. Sedangkan variabel bebas lainnya berpengaruh negatif.

Kata kunci: Perilaku petani; regresi stepwise; tanaman sela

\section{PENDAHULUAN}

Karet merupakan komoditas penyumbang devisa terbesar ekspor nonmigas Sumatera Selatan (Sumsel). Nilai ekspor karet pada tahun 2014 USD 1,613 miliar atau memberikan kontribusi sebesar $76 \%$ terhadap total ekspor non-migas Sumsel (USD 2,13 miliar) (Badan Pusat Statistik [BPS] Sumsel, 2014). Pencapaian tersebut dikarenakan luas areal perkebunan karet mencapai $665.060 \mathrm{Ha}$, 
yaitu Tanaman Belum Menghasilkan (TBM) 102.343 Ha, Tanaman Menghasilkan (TM) 553.559 Ha dan Tanaman Rusak (TR) 9.158 Ha (BPS, 2012). Walaupun karet merupakan salah satu komoditi andalan, namun produktivitas perkebunan karet di Sumsel masih rendah. Salah satu penyebabnya adalah penguasaan lahan perkebunan karet di Sumsel 93\% dikuasai oleh perkebunan rakyat yang pemeliharaannya belum optimal.

Tanaman sela karet merupakan usaha pendukung untuk mengoptimalkan pengelolaan usahatani karet yang bertujuan memberikan tambahan pendapatan pada masa tanaman karet belum menghasilkan, meningkatkan penggunaan tenaga kerja, serta menambah pupuk yang bermanfaat bagi tanaman karet dan tanaman sela. Menurut Rosyid (1989) dan Rosyid dan Wibawa (1996), salah satu alternatif yang dapat dikembangkan untuk meningkatkan pendapatan petani karet adalah melalui sistem usahatani terpadu seperti menanam tanaman sela. Ada beberapa keuntungan dari penanaman tanaman sela yaitu:

1) Tanaman sela dapat berfungsi sebagai tanaman penutup tanah, sehingga dapat untuk konservasi lahan karet dan meningkatkan produktivitas tanaman karet.

2) Efisiensi biaya usahatani dan tenaga kerja, karena biaya pemeliharaan tanaman karet dapat dilakukan bersama-sama dengan pemeliharaan tanaman sela.

3) Meningkatkan kontinuitas dan besaran pendapatan petani.

4) Petani dapat menyediakan kebutuhan pangan keluarganya secara swadaya.

5) Lahan kosong di antara gawangan karet dapat dimanfaatkan, meningkatkan pemeliharaan kebun karet, dan memberikan pendapatan lebih dini.

Usahatani karet dengan menanan tanaman sela seperti padi gogo, jagung, kedelai dan kacang hijau memberikan pengaruh positif terhadap pertumbuhan karet. Hal ini ditunjukkan dengan lilit batang tanaman karet pada umur 15 bulan mencapai $10,5 \mathrm{~cm}$. Produksi yang dicapai padi gogo varietas Way Rarem 1,62 - 2,74 ton/Ha, kedelai $115,5 \mathrm{~kg} / \mathrm{Ha}$ dan kacang hijau $490 \mathrm{~kg} / \mathrm{Ha}$ dan hasil analisis usahatani pada tahun pertama, ternyata usahatani padi gogo di sela tanaman karet mampu membiayai usahatani karet, serta kebun karet tetap terawat dan terpelihara (Djamhuri et al., 1998 ; Suriansyah, 1998).

Selain memberi tambahan pendapatan, penanaman tanaman sela seperti tanaman pangan dan holtikultura turut memberikan kontribusi terhadap persediaan tanaman pangan seperti beras sehingga dapat mendukung program ketahanan pangan baik dalam skala regional maupun nasional. Hal tersebut perlu dilakukan mengingat lahan perkebunan karet seluas $75 \%$ yang belum dimanfaatkan secara maksimal (Sunarwidi, 1987).

Dengan penanaman tanaman sela akan meningkatkan pendapatan petani, disamping itu membaiknya harga karet maka akan meningkatkan pendapatan petani karet. Diduga, dengan meningkatnya pendapatan petani akibat peningkatan harga karet, menyebabkan kecenderungan petani untuk tidak lagi menanam tanaman sela. Namun, kenyataannya masih banyak petani yang tetap menanam tanaman sela diantara karet pada umur $0-3$ tahun. Oleh karena itu penelitian ini perlu dilakukan untuk mengidentifikasi dan menganalisis faktor-faktor penentu yang menyebabkan petani tetap melakukan tanaman sela karet. Kebiasaan petani yang tetap memanfaatkan kebun karet selama TBM untuk menanam tanaman sela maka secara tidak langsung akan menambah pendapatan petani serta dapat meningkatkan tingkat kesejahteraan petani karet rakyat.

\section{BAHAN DAN METODE}

Penelitian dilakukan pada bulan April dan Juni 2013. Lokasi penelitian di Desa Pangkul (Kabupaten Muara Enim), Desa Lubuk Bandung (Kabupaten Ogan Ilir) dan Desa Marta Jaya (Kabupaten Ogan Komering Ulu). Sampel yang digunakan berjumlah 43 petani dan pengambilan sampel menggunakan metode purposive sampling dimana responden dipilih dengan sengaja yaitu dengan memilih petani yang memiliki kebun karet TBM berumur 0-3 
tahun. Survei dilakukan di lokasi petani lokal maupun pendatang. Pengambilan data dilakukan dengan metode survei melalui wawancara langsung dengan responden menggunakan kuesioner terstruktur. Jenis data yang dikumpulkan antara lain profil petani, status lahan yang dimiliki, jenis pekerjaan petani, manfaat menanam tanaman sela, jarak kebun petani ke rumah dan pasar, serta informasi lain yang relevan.

Data dianalisis secara deskriptif dan kuantitatif dengan menggunakan analisis regresi stepwise. Analisis regresi digunakan untuk mengukur besarnya pengaruh variabel bebas terhadap variabel terikat (Gujarati, 2006). Untuk mendapatkan model terbaik, digunakan analisis regresi stepwise. Model terbaik harus bebas dari multikolinieritas, autokorelasi dan heteroskedastisitas (Nazir, 2005). Variabel bebas yang digunakan sebanyak 14 variabel. Model direpresentasikan sebagai berikut:

$\mathrm{Y}=\mathrm{C}+\mathrm{aX} 1+\mathrm{bX} 2+\mathrm{cX} 3 \ldots .+\mathrm{nX} 14+\varepsilon \ldots \ldots(1)$

Dimana :

Y : Perilaku petani (dummy 1 : menanam tanaman sela ; 0 : tidak menanam)

$\mathrm{X} 1$ : Harga karet $(\mathrm{Rp} / \mathrm{Kg})$

$\mathrm{X} 2$ : Pendapatan tanaman sela $(\mathrm{Rp} / \mathrm{bln})$

$\mathrm{X} 3$ : Penghasilan petani per bulan (Rp/bln)

X4 : Umur petani karet (Tahun)

X5 : Pengalaman berkebun karet (Tahun)

X6 : Ketersediaan tenaga terja keluarga (HOK/minggu)

pX7: Jarak kebun petani ke jalan poros $(\mathrm{Km})$

X8 : Jarak kebun petani ke pemukiman (Km)

X9 : Jarak kebun petani ke pasar $(\mathrm{Km})$

$\mathrm{X} 10$ : Luas lahan petani karet (Ha)

X11: Pendidikan petani (Tahun)

$\mathrm{X} 12$ :Tujuan menanam tanaman sela (dummy 1: Dijual ; 0 : konsumsi sendiri)

X13: Status lahan petani (dummy 1 : sewa ; $0:$ milik sendiri)

X14: Pekerjaan pokok (dummy 1 : nonpetani karet; 0 : Petani karet)

C : Konstanta

$\varepsilon \quad$ : Error teknis

Penelitian ini menggunakan respon/terikat berbentuk dummy. Tidak seperti regresi linier biasa, penggunaan regresi logistik memiliki kelebihan dalam hal pelanggaran beberapa asumsi yang harus ada pada regresi linier biasa seperti asumsi error dari model regresi yang didapat tidak menyebar normal dan ragam (variance) dari error tidak homogen (terjadi heteroskedastisitas pada ragam error). Sehingga dari kelebihan tersebut terdapat kelemahan dengan menggunakan model ini yaitu dengan melanggarnya asumsi ragam dari eror yang tidak homogen dapat menjadikan ragam menjadi besar. Estimasi nilai Y juga terletak pada range yang sangat luas (dapat berada di luar interval 1-0). Dengan demikian secara matematis penggunaan regresi logistik menjadi lebih mudah digunakan.

Berdasarkan analisis regresi stepwise maka akan mendapatkan variabel bebas terbaik. Terdapat dua jenis pengujian dalam analisis regresi stepwise. Pengujian tersebut adalah pengujian parameter dan pengujian variabel.

\section{Pengujian Parameter Model (Uji F)}

Tujuan pengujian ini adalah untuk melihat apakah variabel bebas (independent) yang digunakan secara bersama-sama berpengaruh nyata pada variabel tak bebas (dependent). Uji statistik yang digunakan adalah uji $\mathrm{F}$.

2. Pengujian Parameter Variabel (Uji t) Tujuan dari pengujian ini adalah untuk mengetahui apakah koefisien regresi dari masing-masing variabel independent $(\mathrm{X})$ yang digunakan berpengaruh signifikan terhadap variabel dependent $(\mathrm{Y})$. Uji statistik yang digunakan adalah uji t dan taraf nyata digunakan adalah a $5 \%$.

Kegiatan penelitian di lapangan dengan melihat 3 faktor yaitu faktor internal, faktor eksternal serta faktor bio fisik. Informasi yang dihasilkan dari faktor internal berupa data primer yaitu profil petani, luas pemilikan lahan, luas lahan yang dibuka, jumlah anggota keluarga dan pendapatan keluarga tani. Faktor eksternal berupa informasi atau data sekunder tentang jumlah tenaga kerja luar keluarga, ketersediaan tenaga kerja upahan, upah buruh, jarak kebun dari pemukiman, jarak kebun dari jalan utama, jarak kebun dari 
akses pasar, pemasaran hasil, harga jual tanaman sela dan harga jual karet, serta pola pengelolaan kebun. Sedangkan faktor bio fisik yang diamati antara lain jenis tanaman sela yang ditanam dan jenis bibit tanaman karet.

\section{HASIL DAN PEMBAHASAN}

\section{Karakteristik Responden}

Pada penelitian ini responden yang diamati berjumlah 43 orang terdiri atas $58 \%$ penduduk pendatang dan $42 \%$ penduduk lokal. Petani lokal memiliki kecenderungan memanfaatkan hasil tanaman sela untuk memenuhi kebutuhan sendiri, sedangkan penduduk pendatang menjual hasil tanaman sela kepada pedagang untuk menambah penghasilan keluarga. Sebagian besar petani berpendidikan SD (55\%) dan SMA (26\%). Usia petani rata-rata di bawah 50 tahun, sehingga petani tersebut masih memiliki tenaga dan giat untuk merawat dan memelihara kebunnya dengan baik. Berikut ini merupakan profil umum responden (Tabel 1).

Data pada Tabel 1 juga menunjukkan bahwa penduduk di lokasi penelitian mayoritas berasal dari luar wilayah maupun penduduk lokal. Pada wilayah desa Marta Jaya mayoritas berasal dari penduduk non lokal, hal ini karena desa Marta Jaya merupakan wilayah trangsmigrasi dari pulau Jawa. Penduduk di Desa Pangkul masih didominasi oleh petani lokal. Sebaliknya Desa Lubuk Bandung mayoritas diduduki oleh penduduk lokal. Karakteristik responden lainnya adalah berdasarkan pengusahaan usahatani karet dan tingkat pendidikan. Tingkat pendidikan petani mayoritas adalah lulusan SD. Namun, tidak membuat petani minim akan pengetahuan berkebun karet. Pengetahuan berkebun karet didapat secara turun menurun karena berkebun karet merupakan pekerjaan yang sudah lama dilakukan petani. Selain itu juga petani mendapatkan pengetahuan berkebun karet dari kegiatan penyuluhan yang diselenggarakan oleh pihak pemerintah daerah dan pihak swasta. Dari kegiatan tersebut pengetahuan petani akan berkembang. Sedangkan untuk karakteristik petani berdasarkan usia, kegiatan usahatani karet di Lubuk Bandung didominasi usia tua dibandingkan dengan usia muda, Marta Jaya banyak diusahakan oleh petani yang berusia di bawah 40 tahun. Sedangkan Pangkul lebih banyak dikerjakan oleh petani yang berusia di

Tabel 1. Profil responden

Table 1. Profile of respondents

\begin{tabular}{llcr}
\hline $\begin{array}{c}\text { Profil petani } \\
\text { Farmer's profile }\end{array}$ & $\begin{array}{c}\text { Uraian } \\
\text { Description }\end{array}$ & $\begin{array}{c}\text { Total } \\
\text { Total }\end{array}$ & $\begin{array}{c}\text { Persentase } \\
\text { Percentage } \\
\text { (\%) }\end{array}$ \\
\hline Asal Petani & Pendatang & 25 & 58 \\
& Lokal & 18 & 42 \\
\hline \multirow{3}{*}{ Pendidikan } & SD & 24 & 55 \\
& SMP & 7 & 17 \\
& SMA & 11 & 26 \\
Umur & Sarjana & 1 & 2 \\
& $\leq 40$ & 15 & 35 \\
& $41-49$ & 14 & 33,5 \\
\hline
\end{tabular}

Sumber : Data primer diolah

Source : Analysis of primary data 
bawah 50 tahun. Secara umum semua petani karet memiliki potensi tenaga kerja dalam keluarga yang cukup untuk mengerjakan kegiatan usahatani karet. Potensi tenaga kerja dalam keluarga di Desa Marta Jaya rata-rata sebesar 4,09 $\mathrm{HOK} /$ minggu/KK, di Desa Pangkul ratarata sebesar 8,8 HOK/minggu/KK dan Desa Lubuk Bandung rata-rata sebesar 7,39 $\mathrm{HOK} / \mathrm{minggu} / \mathrm{KK}$. Data tersebut menunjukkan bahwa ketersediaan tenaga kerja dalam keluarga cukup dan tidak ada alasan petani untuk tidak sempat memelihara kebun dengan baik dan memanfaatkan kebun karet TBM 0-3 tahun untuk tanaman sela. Kondisi kebun petani yang menanam tanaman sela dapat dilihat pada Gambar 1. Kondisi kebun karet memanfaatkan lahan dengan menanam tanaman sela seperti nanas, cabai, pisang, padi dan sayuran lainnya. Adanya tanaman sela berdampak juga terhadap kebersihan kebun dan kebun karet terpelihara dengan baik.

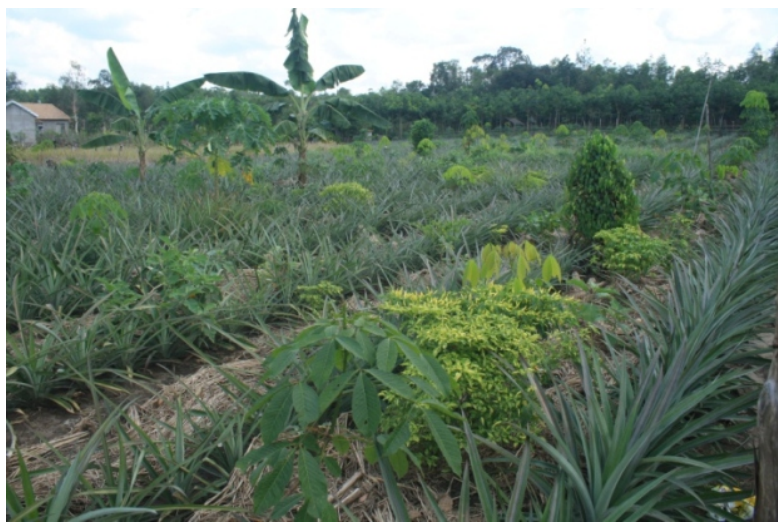

Gambar 1a. Tanaman sela di Desa Pangkul Figure 1a. Intercropping at Pangkul

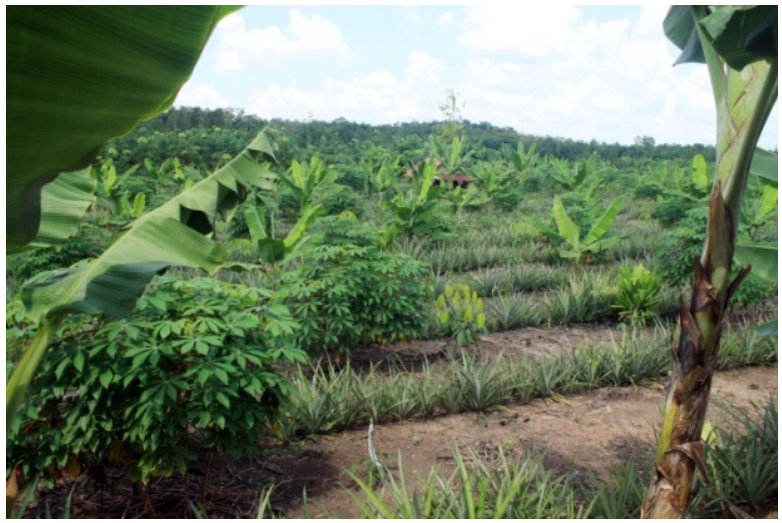

Gambar 1c. Tanaman sela di Desa Lubuk Bandung

Figure 1c. Intercropping at Lubuk Bandung

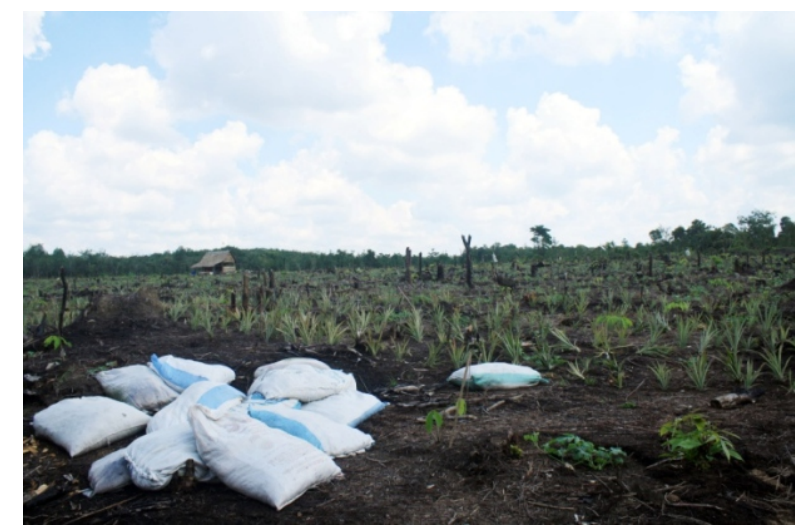

Gambar 1b. Tanaman sela di Desa Marta Jaya Figure $1 b . \quad$ Intercropping at Marta Jaya

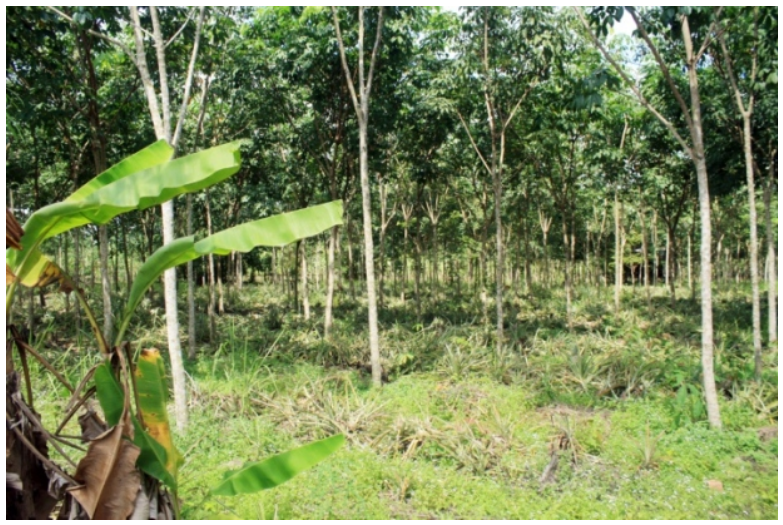

Gambar 1d. Tanaman sela di Desa Pangkul Figure 1d. Intercropping at Pangkul 


\section{Faktor-Faktor Dominan yang Mempengaruhi Petani Menanam Tanaman Sela}

Berdasarkan hasil analisis stepwise terdapat 5 variabel bebas dari 14 variabel bebas yang memiliki hubungan kuat terhadap perilaku petani untuk menanam tanaman sela. Tabel 2 menyajikan hasil analisis stepwise.

Tabel 2 menunjukkan bahwa terdapat lima variabel bebas yang memiliki hubungan kuat terhadap variabel tidak bebas dibandingkan variabel bebas lainnya. Ada sembilan variabel yang tidak miliki hubungan kuat terhadap faktor penentu untuk menanam tanaman sela adalah variabel harga karet, penghasilan petani, umur petani, ketersediaan tenaga kerja, jarak kebun petani ke jalan poros, jarak kebun petani ke permukiman, jarak kebun petani ke pasar, luas lahan petani dan status lahan. Berdasarkan kondisi dilapangan bahwa kesembilan variabel tersebut tidak mempengaruhi petani untuk menentukan petani untuk menanam tanaman sela. Sedangkan kelima variabel bebas yang telah terseleksi melalui model berdasarkan kondisi lapangan memang memiliki hubungan terhadap penentuan petani untuk menanam tanaman sela. Model yang sudah terseleksi tersebut tersebut sudah terbebas dari sifat multikolinieritas. Hal tersebut dapat dilihat pada nilai VIF < 10. Selain itu tidak terdapat korelasi kuat antar peubah bebas. Hal tersebut dapat dilihat dari nilai pearson correlation kurang dari 0,5 (Tabel 3).

Berdasarkan analisis regresi stepwise variabel yang digunakan adalah $\mathrm{X} 2, \mathrm{X} 5, \mathrm{X} 11, \mathrm{X} 12$ dan X14. Dari analisis tersebut dihasilkan model persamaan sebagai berikut :

$$
\begin{array}{r}
\mathrm{Y}=1.07+0,000001 \mathrm{X} 2+0,003 \mathrm{X} 5-0,03 \mathrm{X} 11 \\
+0,16 \mathrm{X} 12-0,078 \mathrm{X} 14 \ldots \ldots \ldots \ldots \ldots(1)
\end{array}
$$

Selanjutnya mengacu pada analysis of variance (ANOVA) semua variabel bebas yang digunakan secara serempak berpengaruh nyata terhadap perilaku petani dalam menanam tanaman sela. Hal tersebut dapat dilihat dari nilai P-Value 0,000. Nilai tersebut lebih kecil

Tabel 2. Hasil seleksi variabel yang memiliki hubungan kuat untuk menanam tanaman sela

\begin{tabular}{|c|c|c|c|c|c|}
\hline $\begin{array}{c}\text { Langkah } \\
\text { Step }\end{array}$ & 1 & 2 & 3 & 4 & 5 \\
\hline Konstanta & 1,119 & 1,044 & 0,995 & 1,122 & 1,07 \\
\hline $\mathrm{X} 11$ & $-0,027$ & $-0,026$ & $-0,026$ & $-0,032$ & $-0,03$ \\
\hline T-Value & $-3,410$ & $-3,580$ & $-3,740$ & $-4,150$ & $-4,20$ \\
\hline P-Value & 0,001 & 0,001 & 0,001 & 0,000 & 0,00 \\
\hline $\mathrm{X} 12$ & & 0,159 & 0,191 & 0,165 & 0,16 \\
\hline T-Value & & 2,870 & 3,400 & 2,890 & 2,88 \\
\hline P-Value & & 0,006 & 0,002 & 0,006 & 0,00 \\
\hline $\mathrm{X} 2$ & & & 0,000 & 0,000 & 0,000001 \\
\hline T-Value & & & 1,920 & 1,790 & 1,67 \\
\hline P-Value & & & 0,063 & 0,082 & 0,103 \\
\hline $\mathrm{X} 14$ & & & & $-0,080$ & $-0,078$ \\
\hline T-Value & & & & $-1,630$ & $-1,630$ \\
\hline P-Value & & & & 0,112 & 0,112 \\
\hline $\mathrm{X} 5$ & & & & & 0,003 \\
\hline T-Value & & & & & 1,600 \\
\hline P-Value & & & & & 0,118 \\
\hline F-Value & & & & & 6,94 \\
\hline $\operatorname{Pr}>F$ & & & & & 0,000 \\
\hline $\mathrm{R}^{2}$ adj & & & & & $48,4 \%$ \\
\hline
\end{tabular}
Table 2. The selection result of variable that had a strong link to plant intercrops 
Tabel 3. Kolerasi antar peubah Table 3. Colerations between variables

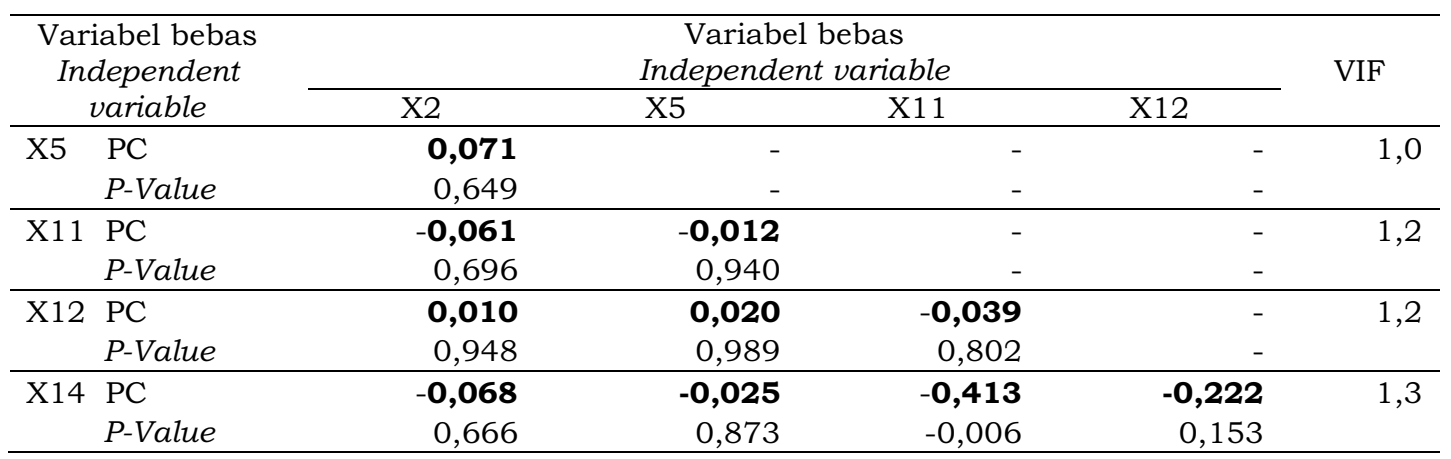

Keterangan (Remarks) : $\quad$ PC : Pearson Correlation

dibandingkan dengan nilai kesalahan 0,05 (taraf nyata $5 \%$ ) dan berdasarkan uji F, nilai $F$ hitung $(6,94)$ dan $F$ tabel $(2,61)$ yang berarti nilai $F$ hitung $>F$ tabel. Hasil analysis of variance (ANOVA) dapat dilihat pada Tabel 4.

Pengaruh variabel bebas secara individu terhadap variabel tidak bebas dapat dilihat dari uji t. Jika nilai t-hitung $>$ ttabel atau nilai $\mathrm{P}$-value < a 15\%, maka variabel bebas tersebut berpengaruh nyata terhadap variabel tidak bebas. Berdasarkan hasil regresi stepwise diperoleh nilai $R$ Square $\left(R^{2}\right)$ 48,4\% yang artinya lima variabel bebas tersebut mampu menjelaskan perilaku petani untuk menanam tanaman sela sebesar 48,4\%, sedangkan 51,6\% dijelaskan oleh variabel lain yang tidak diterangkan dalam model. Untuk melihat signifikansi variabel bebas terhadap perilaku petani menanam tanaman sela dapat dilihat dari nilai $P$-value lebih kecil dari a $15 \%$. Nilai $P$-value dapat dilihat pada Tabel 5.

Berdasarkan Tabel 5, kelima variabel bebas berpengaruh signifikan terhadap perilaku petani dalam menanam tanaman sela pada taraf nyata a $15 \%$. Faktor-faktor dominan yang mempengaruhi petani dalam menanam tanaman sela adalah:

1. Pendapatan tanaman sela (X2)

Pendapatan dari tanaman sela berpengaruh nyata terhadap petani untuk

Tabel 4. Hasil Analysis of Variance (ANOVA)

Table 4. Result of analysis of variance

\begin{tabular}{lrrrrr}
\hline Sumber & \multicolumn{1}{l}{ DF } & \multicolumn{1}{l}{ SS } & \multicolumn{1}{l}{ MS } & \multicolumn{1}{l}{$F$} & $P$ \\
Source & 5 & 0,472 & 0,976 & 6,94 & 0,000 \\
\hline Regression & 37 & 0,504 & 0,013 & & \\
Residual Error & 42 & 0,976 & & & \\
Total & & & & & \\
\hline
\end{tabular}

Sumber: Data primer diolah

Source : Analysis of primary data 
Tabel 5. Hasil regresi stepwise usahatani karet rakyat di Sumatera Selatan

Table 5. Result of stepwise regression of farming system smallholder in South Sumatera

\begin{tabular}{lrrr}
\hline \multicolumn{1}{c}{$\begin{array}{c}\text { Prediksi } \\
\text { Predictor }\end{array}$} & Koefisien & \multicolumn{1}{c}{$T$} & \\
\hline Coefficient & 1,07 & - & 0,00 \\
Konstanta & 0,000001 & 1,67 & 0,10 \\
X5 & 0,003 & 1,60 & 0,11 \\
X11 & $-0,031$ & $-4,20$ & 0,000 \\
X12 & 0,161 & 2,88 & 0,007 \\
X14 & $-0,078$ & $-1,63$ & 0,11 \\
\hline \multicolumn{1}{c}{$=0,116727$} & R-Sq $=48,4 \%$ & R-Sq(adj) $=41,4 \%$ & \\
\hline
\end{tabular}

Sumber : Data primer diolah

Source : Analysis of primary data

menanam tanaman sela. Hal tersebut dapat dilihat pada nilai P-Value 0,10 lebih kecil dari taraf nyata a $15 \%$. Berdasarkan kondisi lapang petani yang menanam tanaman sela, petani lebih tertarik pada tanaman yang pasarnya sudah jelas seperti nanas, cabai, pare, kacang panjang dan sebagainya. Hal ini berbanding lurus dengan hasil penelitian sebelumnya yang dilakukan oleh Rajasekharan dan Veeraputharan (2002) yang menyatakan bahwa petani di Kerala (India) memilih tanaman pisang, nenas, ubi kayu, elephant yam dan jahe karena memberikan pendapatan yang tinggi dibandingkan dengan tanaman sela yang lain. Variabel ini memiliki hubungan yang positif. Hal tersebut dapat dilihat dari nilai koefesien regresi $(0,000001)$, artinya setiap ada peningkatan pendapatan dari tanaman sela maka perilaku petani akan cenderung untuk menanam tanaman sela. Jumlah pendapatan dari tanaman sela sangat tergantung pada jenis tanamannya. Pendapatan dan $\mathrm{R} / \mathrm{C}$ rasio yang diterima petani dari berbagai macam jenis tanaman sela dapat dilihat pada Tabel 6.

Berdasarkan Tabel 6, tanaman sela yang memberikan keuntungan tertinggi adalah cabai. Hal tersebut dapat dilihat dari nilai $\mathrm{R} / \mathrm{C}$ rasio 2,63 - 2,7 yang menunjukkan bahwa setiap biaya yang dikeluarkan sebesar IDR 1,00 maka akan mendapatkan pendapatan kotor sebesar IDR 2,63 - 2,7. Secara ekonomi usahatani tananaman sela cabai menguntungkan karena nilai $\mathrm{R} / \mathrm{C}$ rasio yang diberikan $>1$. Rata-rata pendapatan dari masing-masing tanaman sela beragam setiap jenis tanaman sela tergantung pada harga jual dan produksi. Penanaman tanaman sela secara berkesinambungan akan memberikan pendapatan lebih untuk petani karet rakyat disamping pendapatan dari karet (Agustina, Syarifa, Nancy, \& Rosyid, 2010). Kontribusi tanaman sela terhadap pendapatan petani sangat berpengaruh. Pendapatan yang dihasilkan dari tanaman sela merupakan yang terbesar setelah penghasilan utama yaitu karet. Oleh sebab itu introduksi tanaman sela yang prospektif ke dalam sistem usahatani berbasis karet akan meningkatkan pendapatan petani. Untuk melihat kontribusi tanaman sela terhadap pendapatan keluarga dapat dilihat pada Tabel 7.

\section{Pengalaman berkebun karet (X5)}

Pengalaman berkebun karet merupakan faktor penentu untuk menanam tanaman sela. Hal tersebut dapat dilihat pada nilai P-Value 0,11 lebih kecil dari taraf nyata a $15 \%$. Variabel ini berpengaruh positif terhadap perilaku petani dalam menanam tanaman sela. Hal tersebut dapat dilihat pada koefisien bernilai positif $(0,003)$. Artinya semakin lama pengalaman petani dalam berkebun maka akan mempengaruhi petani untuk menanam tanaman sela. Hal ini berbanding lurus dengan hasil penelitian sebelumnya yang dilakukan oleh Herath 
Tabel 6. Pendapatan petani dari menanam tanaman sela per $1 / 2$ Ha per tahun Table 6. Farmers income from intercropping / 1/2 $\mathrm{Ha} /$ year

\begin{tabular}{llrrrrr}
\hline No & $\begin{array}{c}\text { Jenis } \\
\text { tanaman sela } \\
\text { Kind of } \\
\text { intercropping }\end{array}$ & $\begin{array}{c}\text { Harga } \\
\text { Price } \\
\text { (IDR } \\
\text { OOO) }\end{array}$ & $\begin{array}{c}\text { Penerimaan } \\
\text { Revenue } \\
\text { (IDR 000) }\end{array}$ & $\begin{array}{c}\text { Biaya produksi } \\
\text { Cost of } \\
\text { productin } \\
\text { (IDR 000) }\end{array}$ & $\begin{array}{c}\text { Pendapatan } \\
\text { Income } \\
\text { (IDR 000) }\end{array}$ & $\begin{array}{c}\text { R/C Rasio } \\
\text { R/C Ratio }\end{array}$ \\
\hline 1 & Cabai & $20000-50000$ & $7355-18990$ & $12645-31010$ & $2,63-2,70$ \\
2 & Pare & $2-2,5$ & $5400-10000$ & $3215-5244$ & $2185-4756$ & $1,68-1,91$ \\
3 & Padi & 3,5 & 7000 & 4440 & 2560 & 1,58 \\
4 & Nenas & 2,5 & 18750 & 9173 & 9557 & 2,04 \\
5 & Kacang Panjang & $1,5-3$ & $1680-10500$ & $1505-4730$ & $560-5770$ & $1,12-2,22$ \\
\hline
\end{tabular}

Sumber : Data Primer, 2013

Source : Primary data, 2013

Tabel 7. Kontribusi penerimaan petani Table 7. Revenue contribution farmers

\begin{tabular}{lccc}
\hline \multirow{1}{*}{$\begin{array}{c}\text { Desa } \\
\text { District }\end{array}$} & \multicolumn{3}{c}{$\begin{array}{c}\text { Kontribusi penerimaan } \\
\text { Revenue contribution } \\
(\%)\end{array}$} \\
\cline { 2 - 4 } & $\begin{array}{c}\text { Karet } \\
\text { Rubber }\end{array}$ & $\begin{array}{c}\text { Luar usahatani } \\
\text { Out farming system }\end{array}$ & $\begin{array}{c}\text { Tanaman sela } \\
\text { Intercropping }\end{array}$ \\
\hline Marta Jaya & 85 & 4 & 11 \\
Pangkul & 58 & 2 & 40 \\
Lubuk Bandung & 70 & 4 & 26 \\
\hline
\end{tabular}

dan Takeya (2003) yang menyatakan bahwa dengan lamanya pengalaman berkebun karet maka akan meningkatkan motivasi petani untuk membuat inovasi baru untuk meningkatkan kesejahteraan petani.

Berdasarkan penelitian, rata-rata petani memiliki pengalaman berkebun karet $<10$ tahun $(26 \%), \geq 10$ tahun $(26 \%)$ dan $\geq 20$ tahun (49\%). Dengan pengalaman selama itu petani sudah menjalani masa dimana harga karet masih rendah sampai harga karet meningkat. Oleh karena itu petani karet masih mempertahankan tradisi untuk menanam tanaman sela. Selain mempengaruhi perilaku untuk menanam tanaman sela, pengalaman lama berkebun juga mempengaruhi petani dalam pengambilan keputusan untuk membangun kebun karet (Nurfatiyah, Denmar, \& Prasakti, 2010).

\section{Pendidikan petani (X11)}

Pendidikan formal merupakan faktor penentu dalam menanam tanaman sela. Hal tersebut dapat dilihat pada nilai Pvalue 0,0001 lebih rendah dari taraf nyata a $15 \%$. Namun, variabel ini memiliki hubungan negatif karena koefisien regresi menunjukkan negatif yaitu sebesar -0,031. Angka tersebut menunjukkan bahwa semakin tinggi pendidikan petani maka petani tersebut tidak termovitasi untuk menanam tanaman sela. Hal ini berbanding terbalik dengan hasil penelitian sebelumnya yang dilakukan oleh Nnadi dan Nnadi (2009) yang menyatakan bahwa pendidikan berpengaruh positif terhadap keberlangsungan adopsi tanaman sela jagung/ubi kayu, semakin tinggi pendidikan petani akan mempermudah dalam menganalisis serta menyerap 
teknologi baru sehingga pengolahan usahatani lebih optimal. Petani yang memiliki pendidikan tinggi lebih cenderung akan mencari pekerjaan di perkantoran dibandingkan bekerja di bidang pertanian. Berdasarkan penelitian yang dilakukan tingkat pendidikan petani karet $55 \%$ lulusan SD, 17\% lulusan SMP, 26\% lulusan SMA dan S1 hanya $2 \%$. Namun, pengetahuan tentang tanaman sela diperoleh petani dari pelatihan-pelatihan yang diselenggarakan oleh pemerintah daerah setempat maupun dari program Corporate Social Responsibility (CSR). Pelatihan dan penyuluhan petani karet berguna untuk menambah pengetahuan tentang budidaya karet serta pemanfaatan lahan karet selama TBM.

\section{Tujuan menanam tanaman sela (X12)}

Berdasarkan hasil regresi berganda, variabel ini merupakan faktor penentu untuk menanam tanaman sela. Hal tersebut dapat dilihat pada nilai P-value $(0,000)$ lebih rendah dari taraf nyata a $15 \%$. Koefisien regresi variabel ini bernilai positif yaitu sebesar 0,161, artinya variabel tersebut menunjukkan bahwa tanaman sela dijual untuk menambah pendapatan petani maka petani akan termotivasi untuk menanam tanaman sela apabila dibandingkan dengan tanaman sela yang digunakan untuk konsumsi sendiri. Menanam tanaman sela yang memiliki nilai jual akan menambah pendapatan petani sehingga taraf hidup petani menjadi meningkat (Rajasekharan \& Veeraputharan, 2002). Petani di desa Pangkul menanam tanaman sela yang dapat menghasilkan pendapatan seperti nanas, cabai, kacang panjang, pare dan sebagainya. Dengan menanam tanaman sela tersebut akan membuat petani merawat tanaman sela agar tanaman sela menghasilkan produksi maksimal saat panen. Petani yang menanam tanaman sela untuk konsumsi sendiri lebih jarang ke kebun karena tidak memperhitungkan kerugian jika produksi tanaman sela terkena hama dan penyakit.

\section{Pekerjaan pokok (X14)}

Variabel X14 merupakan variabel dummy dimana nilai (1) non-petani karet dan (0) petani karet. Pekerjaan pokok merupakan variabel yang berpengaruh nyata pada perilaku petani untuk menanam tanaman sela. Hal tersebut dapat dilihat pada nilai P-value 0,11, nilai tersebut lebih kecil dari taraf nyata a $15 \%$. Variabel ini berpengaruh negatif terhadap perilaku petani untuk menanam tanaman sela, hal tersebut dapat dilihat dari nilai koefesien bertanda negatif-0,078.

Nilai koefisien -0,078 artinya bahwa jika petani menjadikan berkebun karet merupakan pekerjaan sampingan maka petani tidak menanam tanaman sela, namun jika petani menjadikan berkebun karet sebagai pekerjaan pokok maka petani tersebut akan menanam tanaman sela. Berdasarkan kondisi lapang bahwa berkebun karet sebagai pekerjaan utama berjumlah $77 \%$ sedangkan $23 \%$ petani menjadikan berkebun karet sebagai pekerjaan sampingan. Walaupun berkebun karet sebagai pekerjaan sampingan namun petani masih tetap menanam tanaman sela.

\section{KESIMPULAN}

Faktor-faktor penentu yang mempengaruhi petani untuk menanam tanaman sela adalah pendapatan dari tanaman sela, pengalaman berkebun karet, pendidikan petani karet, tujuan menanam tanaman sela (untuk dijual) dan pekerjaan pokok (petani karet). Variabel yang berpengaruh positif terhadap perilaku petani untuk menanam tanaman sela adalah pendapatan tanaman sela, pengalaman berkebun karet dan tujuan menanam tanaman sela. Sedangkan yang berpengaruh negatif adalah pendidikan petani dan pekerjaan pokok petani. 
Berdasarkan penelitian yang telah dilakukan petani diharapkan memanfaatkan kebun karet yang usia karetnya masih TBM 0-3 tahun dengan menanam tanaman sela. Pengembangan tanaman sela dapat dilakukan dengan menanam tanaman sela yang memiliki nilai jual. Karena dengan menanam tanaman yang memiliki nilai jual tinggi, Petani karet dapat termotivasi untuk merawat kebun dengan baik serta meningkatkan pendapatan rumah tangganya.

\section{PUSTAKA}

Agustina, D. S., Syarifa, L. F., Nancy, C., \& Rosyid, M. J. (2010). Tanaman sela sebagai tambahan pendapatan bagi petani karet (Studi kasus di Desa Lubuk Bandung, Kabupaten Ogan Ilir, Provinsi Sumatera Selatan). Prosiding Seminar Nasional HasilHasil Penelitian dan Pengkajian (pp. 1180-1187). Palembang, Indonesia : Balai Penelitian dan Pengembangan Daerah Provinsi Sumatera Selatan.

Badan Pusat Statistik. (2012). Statistik perkebunan karet 2010-2012. Jakarta, Indonesia: BPS.

Badan Pusat Statistik Sumsel. (2014). Devisa ekspor nonmigas didominasi karet. Palembang, Indonesia: BPS Sumsel

Djamhuri, M., Noor, A., Suriansyah, S., \& Hartono, A. (1998). Sistem usahatani berbasis karet pada lahan kering beriklim basah di Kalimantan Tengah. Prosiding Lokakarya Strategi Pembangunan Pertanian Wilayah Kalimantan. Banjar Baru, Indonesia : Instalasi Penelitian dan Pengkajian Teknologi Pertanian.

Gujarati, D. (2006). Dasar-dasar ekonometrika. Jakarta, Indonesia: Erlangga.
Herath, P. H. M. U., \& Takeya, H. (2003). Factors determining intercropping by rubber smallholders in Srilanka : a logit analysis. Agricultural Economic, 29(2), 159-168. Doi: 10.1016/S01695150(03)00045-8.

Nazir, M. (2005). Metode Penelitian. Bogor, Indonesia: Ghalia Indonesia.

Nnadi, N. F., \& Nnadi, C. (2009). Farmers' sustained adoption decision behavior of maize/cassava intercrop technology in imo state : lessons for extension policy development. World Rural Observations, 1(2), 87-92.

Nurfatiyah, P., Denmar, D., \& Prasakti, T.O. (2010). Faktor-faktor yang melatarbelakangi keputusan petani dalam mengusahakan komoditi karet di Desa Pasar Terusan Kecamatan Muara Bulian. Jurnal Sosio Ekonomika Bisnis, 13(1), 1-12.

Rajasekharan, P., \& Veeraputharan, S. (2002). Adoption of intercropping in rubber smallholdings in Kerala, India: a tobit analysis. Agroforestry Systems, 56 ( 1 ) , $1-11$. d o i : 10.1023/A:1021199928069.

Rosyid, M. J., \& Wibawa, G. (1996). Pengalaman petani dalam sistem usahatani karet terpadu dengan tanaman gambir di Sumatra Selatan dan Sumatra Barat. Warta Pusat Penelitian Karet, 15(1), 48-56.

Rosyid. M. J. (1989). Tanaman sela kopi di perkebunan karet. Warta Pusat Penelitian Karet, 14(2), 89-101.

Sunarwidi. (1987). Penguasahaan tanaman sela pada gawangan tanaman karet. Prosiding Pertemuan Karet. Pangkalan Berandan, Indonesia: BPP Sungei Putih. 
Suriansyah. (1998). Hasil pengkajian sistem usaha pertanian berbasis karet berwawasan agribisnis di Kabupaten Barito Utara, Kalimantan Tengah. Prosiding Lokakarya Nasional Hasil Penelitian dan Pengkajian Teknologi Pertanian (pp. 65-72). Palangkaraya, Indonesia: Balai Pengkajian Teknologi Pertanian Palangkaraya. 